\title{
Online monitoring of yeast cultivation using a fuel-cell-type activity sensor
}

\author{
Marie-France Favre $\cdot$ Delphine Carrard · \\ Raphaël Ducommun · Fabian Fischer
}

Received: 16 February 2009/Accepted: 22 June 2009/Published online: 25 July 2009

(C) Society for Industrial Microbiology 2009

\begin{abstract}
A microbial fuel-cell type activity sensor integrated into $500 \mathrm{~mL}$ and $3.2 \mathrm{~L}$ bioreactors was employed for ampero- $(\mu \mathrm{A})$ and potentiometric $(\mathrm{mV})$ measurements. The aim was to follow the microbial activity during ethanol production by Saccharomyces cerevisiae and to detect the end of carbohydrate consumption. Three different sensor setups were tested to record electrochemical signals produced by the metabolism of glucose and fructose $(1: 1)$ online. In a first setup, a reference electrode was used to record the potentiometric values, which rose from 0.26 to $0.5 \mathrm{~V}$ in about $10 \mathrm{~h}$ during the growth phase. In a second setup, a combination of ampero- and pseudo-potentiometric measurements delivered a maximum voltage of $35 \mathrm{mV}$. In this arrangement, the pseudo-potentiometric signal changed in a manner that was directly proportional to the amperometric signals, which reached a maximum value of $32 \mu \mathrm{A}$. In a third type of arrangement, a reference electrode was added to the anodic bioreactor compartment to carry out ampero- and potentiometric measurements; this is made possible by the high internal resistance of the cultivation. In this case, the reference potential rose to $0.44 \mathrm{~V}$ while the current maximum recorded by the working electrodes reached $27 \mu \mathrm{A}$. Reference and pseudo-reference electrodes were in all cases $\mathrm{K}_{3} \mathrm{Fe}(\mathrm{CN})_{6} /$ carbon. Electrodes were made of $9 \mathrm{~cm}^{2}$ woven graphite. To compare the electrochemical signals with established values, the metabolism was also monitored for optical density (at $600 \mathrm{~nm}$ ) indicating biomass production. For fructose and glucose conversion, HPLC with an Aminex column and RI detector was used,
\end{abstract}

M.-F. Favre · D. Carrard · R. Ducommun · F. Fischer ( $\square$ ) Life Technologies Institute, HES-SO Sion, University of Applied Sciences Western Switzerland, Route du Rawyl 64, 1950 Sion, Switzerland e-mail: Fabian.Fischer@hevs.ch and ethanol production was analyzed by GC with methanol as internal standard. The combination of amperometric and potentiometric recordings was found to be an ideal setup and was successfully used in reproducible cultivations.

Keywords Microbial activity - Amperometric . Potentiometric $\cdot$ Sensor

\section{Introduction}

In living cells, redox processes generate electrons that are carried through the cytosol to locations where they are used by mediators such as NADPH. The electrons can also be transferred to external electrodes after passing them through the cell membrane. This transfer or "electron tunneling" has a different mechanism for each cell type and can be regarded as an unwanted effect, or as one that is needed for anaerobic respiration in the presence of insoluble electron acceptors, as in Shewanella and Geobacter [6]. The construction of a microbial fuel cell (MFC) is based on the fact that electrons escape from cells. Our intention was to exploit these electrons for electrochemical detection and to observe microbial activity.

The microbial fuel cell activity sensor uses the principle of a fuel cell, where $2 \mathrm{e}^{-} / 2 \mathrm{H}^{+}$reduce an oxidant (Fig. 1). The hydrogen $\left[\mathrm{H}_{2}\right]$ is a virtual intermediate $\left(2 \mathrm{e}^{-} / 2 \mathrm{H}^{+} \rightarrow\right.$ $\left[\mathrm{H}_{2}\right]+1 / 2 \mathrm{O}_{2} \rightarrow \mathrm{H}_{2} \mathrm{O}$ ). The MFC-type activity sensor receives electrons and protons from microbes, generating a directly proportional signal that allows us to follow the metabolic activity. The MFC activity sensor could also be operated with $\mathrm{O}_{2}$ as an oxidant, but the use of $\mathrm{K}_{3} \mathrm{Fe}^{3+}(\mathrm{CN})_{6}$ provides a more stable cathode system.

One well-developed MFC-type activity sensor is the mediatorless biological oxygen demand (BOD) sensor, 


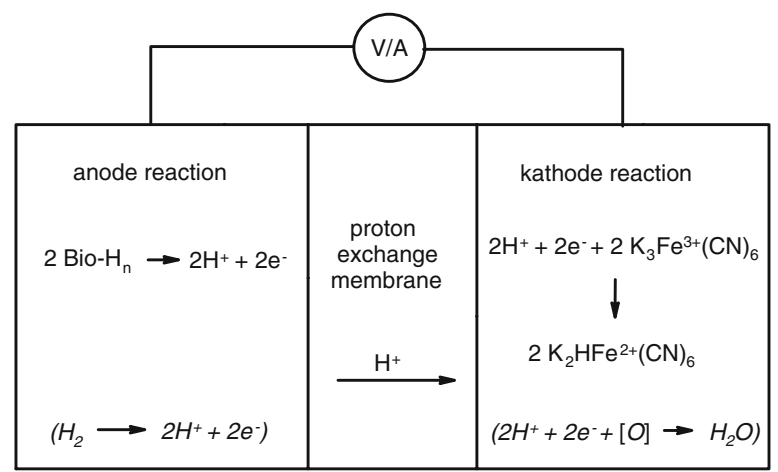

Fig. 1 The microbial fuel-cell-type electrode. In the anode, an electroactive biocompound $\left(\mathrm{Bio}-\mathrm{H}_{n}\right)$ delivers $2 \mathrm{e}^{-} / 2 \mathrm{H}^{+}$to the anode and proton exchange membrane. An oxidant $\mathrm{K}_{3} \mathrm{Fe}^{3+}(\mathrm{CN})_{6}$ is reduced in the cathode. The standard fuel-cell reactions are shown in parentheses

where oxygen reduction is recorded in the anode compartment during cultivation [14]. Such devices have been employed in wastewater treatment for at least five years without any servicing [15]. An external MFC sensor for determining the activity of Saccharomyces cerevisiae for anaerobic cultivation was developed by Halme [25]. The Mattiasson group developed another external online detector that helps to determine the population densities of microorganisms [17]. A variant of the anaerobic MFC-type activity sensor was recently described that takes the form of a bioactivity sensor (BAS) that permits the online measurement of microbial activity by recording the potentiometric signals from various aerobic and anaerobic glucose fermentations [13]. Many laboratories have examined the potential of these MFCs as future electrical power supplies based on biomass like glucose [21], proteins [9], and cellulose [18], and especially on biomass-rich wastewaters from communities [16] or the food industry [19]. Investigations in this field have also led to several other approaches that apply the MFC concept [7]. Additional possible areas of application can be identified. In line with the aforementioned generation of electricity from biomass is the idea of producing power from blood glucose that can be used to drive implanted medical devices such as pacemakers and artificial hearts [3]. Because some implanted devices may need more energy than a small MFC can deliver, recent developments have particularly focused on low-power devices, like implanted glucose sensors connected to an insulin release mechanism [11].

The activity sensor design presented in this paper is different from the one described above due to the fact that the MFC activity sensor is an integral part of the bioreactor. This simplifies the setup for additional measurements. It also allows a particular redox effect of peptone media (see Fig. 3b) to be dealt with in the hours before the fermentation is started-an issue that may be overlooked by external online sensors.
The material used for the working electrodes in the bioreactor was chosen according to biocompatibility first and then ease of use and cost. For online in-process measurement, the electrode surface should accept the electrons liberated from microbes without employing an artificial mediator. In addition, the microbes should not attach themselves to the electrode surface, which can happen rapidly on some surfaces, particularly metallic ones, as shown for gold electrodes [24]. In this respect, woven graphite appeared an ideal, cheap, disposable solution for week-long experiments because it is sufficiently conductive and no further treatment of the surface was needed. The literature primarily describes carbon electrodes and a range of inorganic cathode systems that are especially well suited to power-producing MFCs, as well as biotic systems such as reducing bacteria [8]. The use of an abiotic cathode appears preferable for biosensing, as it ensures a stable potential throughout the cultivation. In addition to the reference mode, the cathode should serve as a working electrode in amperometric measurements. In this case, the cathode was used as a pseudo-reference electrode, and the amount of available reductant determined its usability as reference electrode. The potential change that can occur is negligible. The cathode was also included to provide a different potential from the bioreactor mixture and-in addition to the electrons-to accept protons that were transferred along with the electrons in a 1:1 ratio [4]. The simplest imaginable cathode system used in MFCs is the reduction of oxygen to $\mathrm{H}_{2} \mathrm{O}$ catalyzed by a platinum electrode while bubbling air through the cathodic half-cell [26]. The disadvantage of such an electrode is that oxygen may penetrate through the proton exchange membrane and alter the metabolism of the anaerobic fermentation.

In addition, the proton exchange membrane may eventually allow the invasion of foreign microorganisms into the bioreactor chamber. To prevent complications arising from uncontrollable oxygen crossover and microbial transfer, a $\mathrm{K}_{3} \mathrm{Fe}(\mathrm{CN})_{6} /$ carbon cathode appeared to be more convenient. The solution can be produced from sterile reagents. Potassium hexacyanoferrate(III) is a stable complex and considered to be nontoxic despite its cyano ligands [10]. The $\mathrm{Fe}^{3+}$ ions are reduced to $\mathrm{Fe}^{2+}$, reoxidation in the presence of oxygen is known to be very slow [20], and if no oxygen is present (as in the system employed here) reoxidation should not occur. The cathode solution needs to be exchanged at the end of each experiment. Ethanol production was chosen for this study because it is well established [2] and has become increasingly important to the bioethanol industry. Saccharomyces cerevisiae transforms glucose and fructose into ethanol by the following reaction: $\mathrm{C}_{6} \mathrm{H}_{12} \mathrm{O}_{6} \rightarrow 2 \mathrm{CH}_{3}$ $\mathrm{CH}_{2} \mathrm{OH}+2 \mathrm{CO}_{2}$. We chose the transformation of pure glucose and a mixture of glucose and fructose in a 1:1 ratio with soy peptone and yeast extract as medium, which represents an artificial grape must [1]. 


\section{Materials and methods}

Microbial fuel cell reactor

The $500 \mathrm{ml}$ MFC reactor was constructed in the mechanical shop of the HES-SO Valais at Sion, and was based on the design of a commercially available $9 \mathrm{~mL}$ MFC kit sold by the University of Reading, UK. The body of the $500 \mathrm{~mL}$ MFC was made from Plexiglas ${ }^{\mathrm{TM}}$, the electrodes were woven graphite sheets of various sizes, and a Nafion ${ }^{\mathrm{TM}}$ proton exchange membrane separated the anode and cathode compartments. For the three half-cell setups, the anodic compartment (bioreactor) contained a second opening that allowed an additional cathode compartment to be added.

The $3.2 \mathrm{~L}$ bioreactor was constructed from commercial parts and with the help of a glass blower (see Fig. 5). The lower part of the reactor was equipped with a doublewalled heat jacket, while the upper part was made from a large glass tube $(\varnothing=110 \mathrm{~mm})$ with two extensions $(\varnothing=40 \mathrm{~mm})$ for the electrodes. The stirrer was manufactured from a glass rod $(\varnothing=8 \mathrm{~mm})$, with $3 \times 4$ pallets $\left(9 \times 12.5 \mathrm{~mm}^{2}\right)$.

\section{Yeast-mediated ethanol production}

Saccharomyces cerevisiae was first regenerated in the form of $100 \mathrm{ml}$ preculture containing $1 \%$ yeast extract, $1 \%$ soy peptone, $2 \%$ glucose, and $2 \%$ fructose at $30^{\circ} \mathrm{C}$. The acidity was adjusted to $\mathrm{pH} 5$ and the solution shaken at $30^{\circ} \mathrm{C}$ for $9 \mathrm{~h}$. The preculture was then added at a ratio of 1:50 in order to obtain $500 \mathrm{ml}$ of a solution containing $1 \%$ peptone, $1 \%$ yeast extract, $85 \mathrm{~g} / \mathrm{L}$ glucose, $85 \mathrm{~g} / \mathrm{L}$ fructose or $170 \mathrm{~g} / \mathrm{L}$ glucose.

The $500 \mathrm{~mL}$ MFC reactor was equipped with two woven graphite electrodes $(3.8 \times 7 \mathrm{~cm}$ anode, $3.8 \times 4 \mathrm{~cm}$ cathode) and then placed in an incubator with a stirring plate $(100 \mathrm{rpm})$ and operated at $25^{\circ} \mathrm{C}$ for $5-8$ days. Six milliliters of $0.5 \mathrm{M} \mathrm{K}_{3} \mathrm{Fe}(\mathrm{CN})_{6}$ solution were added to the cathode compartment, covering the graphite electrode.

Amperometric, potentiometric and conductivity measurements

Ampero- and potentiometric measurements at the milli- and microscale were recorded by a VC-960 digital multimeter with a data logger from Voltacraft Plus. In order to operate the multimeters for up to one week, they were connected to GPS-3030 (30 V/3A) laboratory DC power supplies from Emona Instruments. Data were collected in 4 min intervals. At the end of the experiment the data were transferred to a personal computer and processed by the interface program VC920_940_960 furnished with the multimeters. The conductivity in the bioreactor was measured with an Orion
120 conductivity meter equipped with a microprocessor from Müller \& Krempel, Bülach, Switzerland.

\section{Gas chromatography}

The ethanol concentration was determined by GC using an HP5890 instrument with an HP7673 injector and a CP7351 CP-Porabond Q $25 \mathrm{~m}$ column. This method permits solutions to be injected directly from the bioreactor mixture. One milliliter of bioreactor solution and $50 \mu \mathrm{L}$ internal standard $\left(\mathrm{CH}_{3} \mathrm{OH}\right)$ were mixed and diluted to $10 \mathrm{~mL}$, centrifuged and injected. The injection temperature was $85^{\circ} \mathrm{C}$ and the chromatogram was recorded with a gradient of $10^{\circ} \mathrm{C} / \mathrm{min}$ up to $250^{\circ} \mathrm{C}$.

\section{HPLC}

Glucose and fructose concentrations were measured by HPLC using an Agilent 1100 series instrument with a refractive-index detector and a $300 \times 7.8 \mathrm{~mm}$ Aminex HPX-87H separation column for sugar compounds. The eluent was $5 \mathrm{mM} \mathrm{H}_{2} \mathrm{SO}_{4}$ solution, and the column was heated at $35^{\circ} \mathrm{C}$ to facilitate separation.

Optical density

The optical density was recorded with a UV-Vis spectrometer (Biochrom Libra S12) at $600 \mathrm{~nm}$. The results were compared to a blank of the yeast-free peptone from soy media. For high concentrations, the samples were diluted to keep them within an absorption range of 0.1-1.

\section{Results and discussion}

The integrated design of the MFC-type activity sensor with one or two sensing electrodes in the bioreactor compartment provides for several electrochemical measurements. Three of them were more closely examined using the $500 \mathrm{ml}$ bioreactor; they provide up to three sets of recorded data on the same ethanol cultivation.

First, there is the typical two half-cell design that resembles any battery or galvanic cell [12]. The anode (woven graphite $3.8 \times 7 \mathrm{~cm}$ ) is located in the $500 \mathrm{~mL}$ bioreactor compartment and the cathode (woven graphite $3.8 \times 4 \mathrm{~cm}$ ) is separated off by a Nafion proton exchange membrane. This setup permits potentiometric and amperometric measurements.

Starting with this galvanic design, a second cathode was added to the opposite side in the bioreactor. The additional cathode was also based on a $0.5 \mathrm{M} \mathrm{K}_{3} \mathrm{Fe}(\mathrm{CN})_{6}$ solution with a woven carbon electrode. This electrode was used as a reference electrode in potentiometric measurements or as 
a pseudo-reference electrode for recording the amperometric signal and its related potentiometric signal. The cathode cavity contained $6 \mathrm{~mL} 0.5 \mathrm{M} \mathrm{K}_{3} \mathrm{Fe}(\mathrm{CN})_{6}$ solution, the $\mathrm{Fe}^{3+}$ concentration of which decreased slightly from 0.5 to $0.45 \mathrm{M}$ after about $60 \mathrm{~h}$ of cultivation. The change in the concentration of $\mathrm{Fe}^{3+}$ caused by reduction could be modified by utilizing more hexacyanoferrate(III) solution, a higher concentration, or by reducing the electrode surface. In comparison to a customized standard reference electrode, this reference carbon $/ \mathrm{K}_{3} \mathrm{Fe}(\mathrm{CN})_{6}$ combination has the advantage that the electrode can be disposed of after each experiment. In addition, different electrode materials can be considered, which is important in relation to future applications. This is even more important for the anodic compartment, where the electrodes are in contact with the bioreactor mixture. An examination of used graphite electrodes by optical microscopy showed that only a small number of yeast cells had attached themselves to the fine network of the carbon microfibers after 5-7 days of process time. The same electrode material was used in order to obtain comparable results in all experiments. The measurements taken in all experiments were based on the same quantity of glucose and fructose. Because Saccharomyces cerevisiae is known to be glucophilic, glucose is converted more rapidly to ethanol than fructose [5]. However, fructose was also converted quantitatively, although with some delay (Fig. 3); the maximal alcohol concentration was reached when all of the fructose has been consumed. The recorded ethanol concentrations are based on values obtained by GC analysis. These values should be used with caution because of the fact that a small, unquantifiable amount of ethanol may be absorbed during the process in the Plexiglas reactor [23].

MFC activity sensing with one cathode

In the basic two half-cell arrangement (Fig. 2a), the potentiometric measurements show an increasing potential difference, in line with rising microbial activity (Fig. 3a), as indicated by optical density measurements $(600 \mathrm{~nm})$ of the bioreactor mixture. During the growth phase of the yeast cells, the potentiometric value rises to a maximum of $0.5 \mathrm{~V}$ in $20 \mathrm{~h}$ (after inoculation) and remains stable during quantitative glucose and fructose conversion. After two days of cultivation, the potential dropped by approximately $0.1-0.2 \mathrm{~V}$ in one day and often not to the initial level. Ethanol consumption by yeast cells is well described [22] as being in the low \% range and observable (40-60 h) after the end of the sugar conversion (Fig. 3). The number of living cells was determined, and typically about $2.9 \times 10^{7}$ cells $/ \mathrm{ml}$ were found to be present after $40 \mathrm{~h}$ of fermentation. This number decreased by $\sim 50 \%$ during the following $20 \mathrm{~h}$.
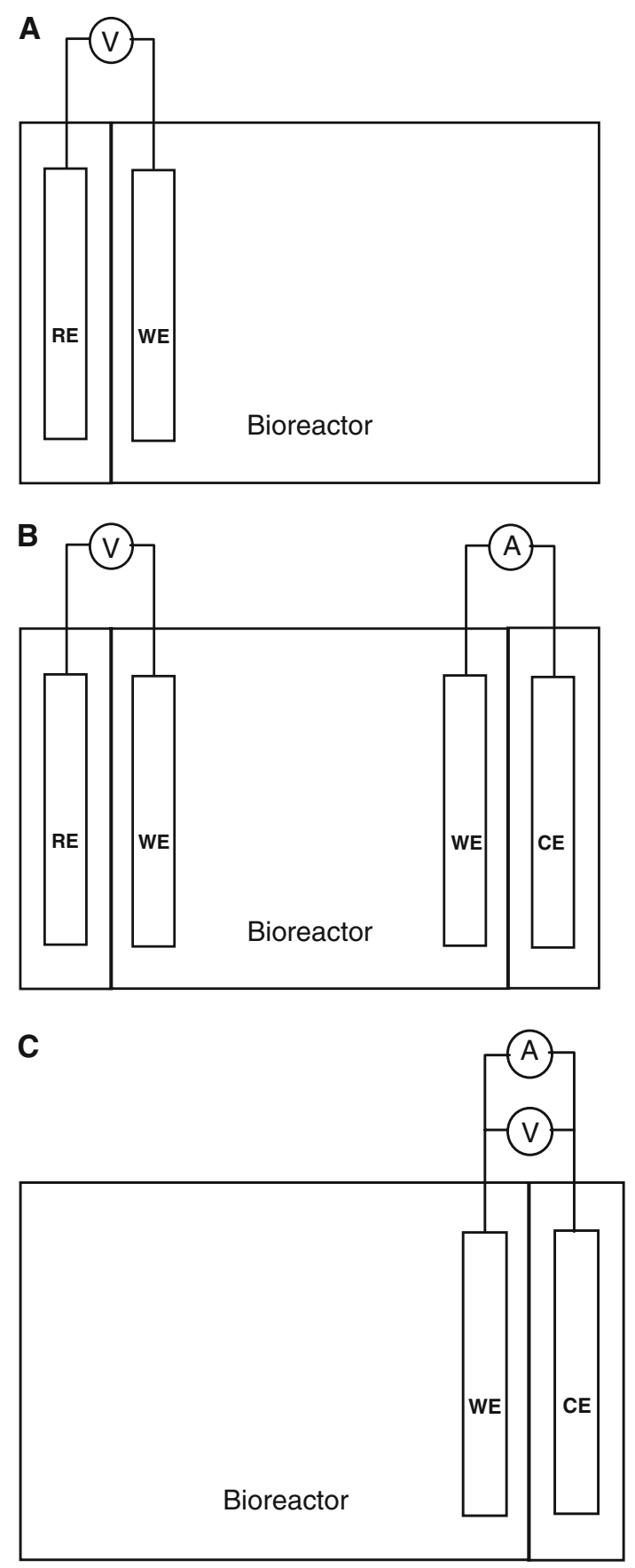

Fig. 2a-c Three MFC-type activity sensor setups for online electrochemical cultivation monitoring. a A two half-cell setup for potentiometric recording. b A three-chamber setup for potentio- and amperometric measurements, including a reference electrode. $\mathbf{c}$ A two half-cell setup with a working electrode for amperometric and pseudo-potentiometric recordings. $R E$ reference electrode; $W E$ working electrode; $C E$ counter electrode

At the end of the sugar metabolism, the potentiometric signal becomes unstable in the presence of foreign conducting materials. This is especially true when taking samples for analytical purposes, and particularly in the sample itself. In order to examine this phenomenon more 
A
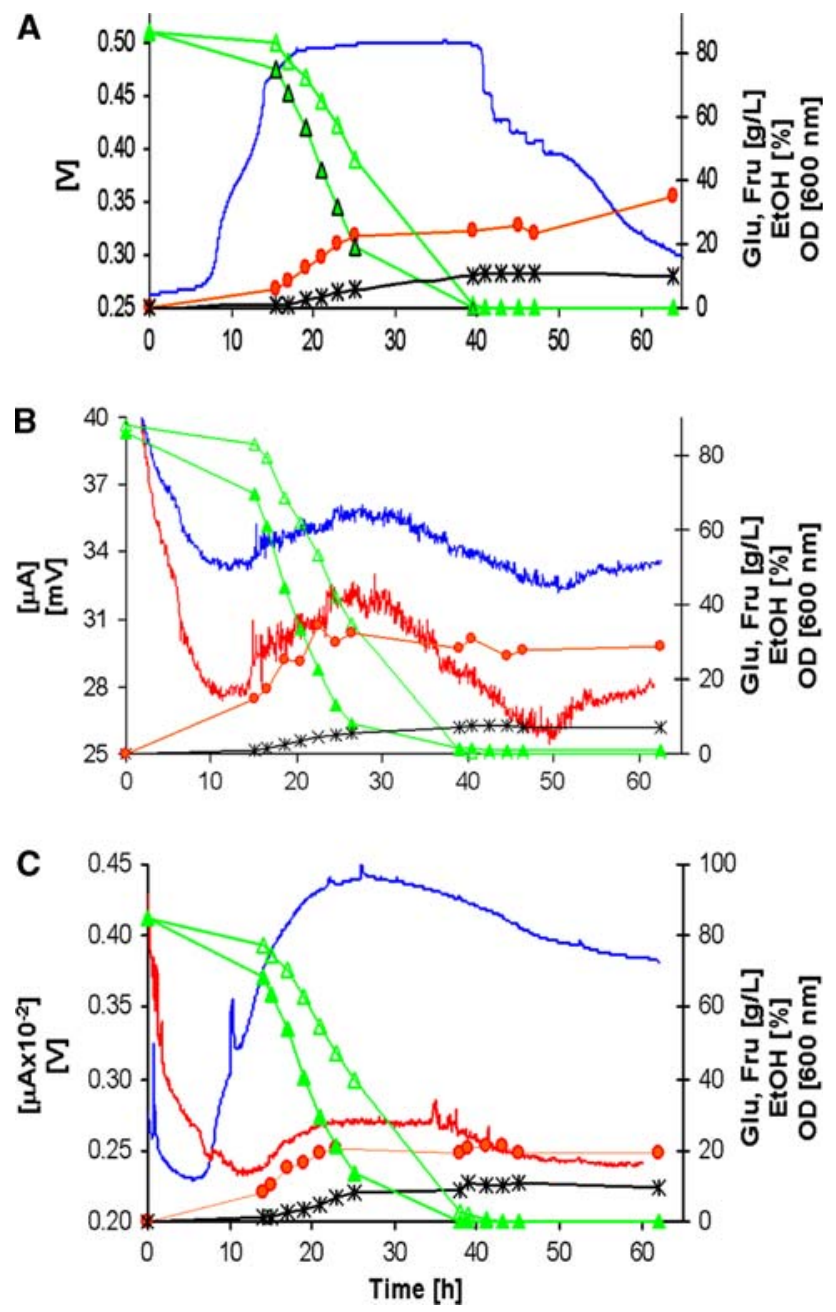

Fig. 3a-c Ethanol production with different activity sensor setups for microbial activity determination. Potentiometric recordings in blue (upper curve). Amperometric recordings in red (lower curve), glucose is represented by filled triangles and fructose by open triangles; the orange filled circles represent OD and the asterisks ethanol, shown in volume \%. a Potentiometric measurement. b Pseudo-reference electrode recording current and tension on the same working electrode. c Potentio- and amperometric measurements

closely, a $5 \mathrm{~L}$ cultivation was carried out in a standard bioreactor, and $6 \mathrm{ml}$ samples were transferred by glass pipette into a mini-MFC on a horizontal shaker. The potentiometric signal can be measured, but the initial values $(\sim 140-220 \mathrm{mV})$ show no direct correlation with the progress of the cultivation. If the samples are observed for 30 min they all develop similar potentials $(\sim 0.35-0.4 \mathrm{~V})$. This result is in line with the observation that both the microbial activity of the microbes and the oxidation states of the electroactive compounds in the culture media determine the current potential.

Why does the cell potential increase in the growth phase from $\sim 0.25$ to $0.5 \mathrm{~V}$ ? This change represents the change in cell potential $E_{\text {cell }}=E_{\text {anode }}-E_{\text {cathode }}$. The standard electrode potential of the cathode is based on $E_{\text {red(cathode) }}^{\circ}$ $=\mathrm{Fe}^{3+}(\mathrm{CN})_{6}^{3-}+1 \mathrm{e}^{-} \rightarrow \mathrm{Fe}^{2+}(\mathrm{CN})_{6}^{4-}=0.36 \mathrm{~V}$. The situation at the anode is complex because electroactive compounds $\left(a_{i}\right)$ of all kinds can interfere, but, based on the assumption that electrons are transferred by Saccharomyces cerevisiae at the moment that they collide with the electrode, we can conclude that the cofactor potential $E_{\text {ox(anode) }}^{\circ}=$ $\mathrm{NADH} / \mathrm{H}^{+} \rightarrow \mathrm{NAD}^{+}+2 \mathrm{H}^{+}+2 \mathrm{e}^{-}=-0.32 \mathrm{~V}$ is a contributor to the electrode potential in the anode compartment. Under standard conditions, the electromotive force is $0.36-(-0.32)=0.68 \mathrm{~V}$ (Eq. 1). A second contributor is the cystine/cysteine redox couple, with a potential $E_{\mathrm{Ox}(\text { anode })}^{\circ}=-0.34 \mathrm{~V}$, which is present in yeast cells and YPG cultivation media. An electromotive force of about $0.70 \mathrm{~V}$ can be regarded as the theoretical upper limit on the voltage generated in the MFC sensor, and the highest recorded standing potential for the reaction mixture in the bioreactor half cell was $0.55 \mathrm{~V}$. This theoretical value was almost matched by not adding a carbohydrate (nutrient) to the cultivation; a value of $0.67 \mathrm{~V}$ was achieved in this case (Fig. 4). The concentration of the redox couple in the cathodic compartment is unaffected in potentiometric monitoring, being constant at $\sim 0.5 \mathrm{M} \mathrm{K}_{3} \mathrm{Fe}^{3+}(\mathrm{CN})_{6}$, while the concentration of $\mathrm{NAD}^{+}$and its reduced form $\mathrm{NADH} / \mathrm{H}^{+}$is a function of the metabolic activity, and varies widely throughout the fermentation. In addition, there is not only a variation in the redox state to be considered but also a variation in the absolute cofactor concentration due to cell growth at the beginning and afterwards, when the substrate concentration drops. Considering all of the redox couples present in the bioreactor, the Nernst equation can be written as follows, where $\Pi\left(a_{i}\right)^{v j}$ is the reaction quotient ( $a_{i}=$ electroactive compounds):

$$
\begin{aligned}
E_{\mathrm{cell}} & =E_{\mathrm{red}\left(\mathrm{Fe}(\mathrm{CN})_{6}^{3-} / \mathrm{Fe}(\mathrm{CN})_{6}^{4-}\right)}^{\circ}+E_{\mathrm{ox}(\text { biorxn })}^{\circ}-\frac{R T}{z F} \ln Q, \\
Q & =\frac{\left[\mathrm{Fe}^{2+}(\mathrm{CN})_{6}^{4-}\right]}{\left[\mathrm{Fe}^{3+}(\mathrm{CN})_{6}^{3-}\right]} \prod_{i}\left[a_{i}^{\text {biorxn }}\right]^{v j}
\end{aligned}
$$

In a second single-cathode setup, the potentiometric and amperometric signals were recorded from the same working electrode (Fig. 2c). The voltage $(\mathrm{mV})$ and current $(\mu \mathrm{A})$ rise and fall simultaneously (Fig. 3b). This arrangement appears to be a more valuable indicator of microbial activity than voltage measurement alone, as the voltage signal drops toward the end of the cultivation in line with the current intensity, indicating the end of the transformation. Considerable oscillations occur in both signals, which were reduced by stirring the solution at $100 \mathrm{rpm}$. The signals drop until they reach a minimum value after $50 \mathrm{~h}$ and then rise again slightly. This minimum value of $\sim 25 \mu \mathrm{A}$ is reached 10-12 $\mathrm{h}$ after all of the glucose and fructose have 


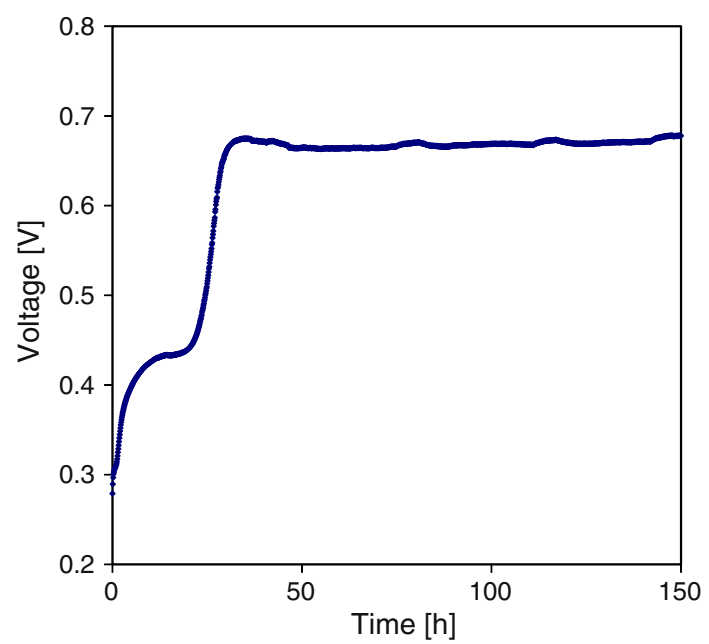

Fig. 4 Constant voltage of a yeast fermentation without any sugar. The potential of $0.67 \mathrm{~V}$ remains stable for hours and corresponds closely to the theoretically calculated cell potential of $0.68 \mathrm{~V}$ between the redox couples $\mathrm{NADH} / \mathrm{H}^{+}$and $\mathrm{Fe}^{3+}(\mathrm{CN})_{6}$

been consumed. In this case, the potential is in line with the amperometric signal because electroactive compounds are oxidized on the electrode and the electrons cause the amperometric signal. We expected not only a close correlation between both signals but also the same oscillations at any time point, but it appears that this is not always the case.

MFC activity sensing with two cathodes

An extension of the integrated MFC type activity sensor was realized by utilizing a three half-cell measuring arrangement (Fig. 2b, c). The bioreactor compartment is again the central part and functions as the anodic half-cell with two woven carbon sheet electrodes. Two cathode compartments separated by a Nafion ${ }^{\mathrm{TM}}$ proton exchange membrane are added on opposite sides of the central bioreactor. This mode permits us to measure current and voltage independently during the same bioreaction. The additional working electrode is used as a reference electrode based on $0.5 \mathrm{M} \mathrm{K}_{3} \mathrm{Fe}(\mathrm{CN})_{6} /$ carbon for potentiometric recording. The current measured by the second working electrode in this setup increases to a maximum value of $27 \mu \mathrm{A}$, which is reached after $21 \mathrm{~h}$ (Fig. 3c). These values are similar in all cultivations. The maximum voltage reached after $28 \mathrm{~h}$ was $0.44 \mathrm{~V}$. For the combined amperometric and potentiometric measurements in the same bioreactor compartment, a small current caused an ohmic drop that resulted in a small decrease of cell voltage; the observed overpotential was about $50-100 \mathrm{mV}$. The low conductivity of $2.4 \mathrm{mS}$ remained stable throughout the entire fermentation. Because of this polarization behavior,

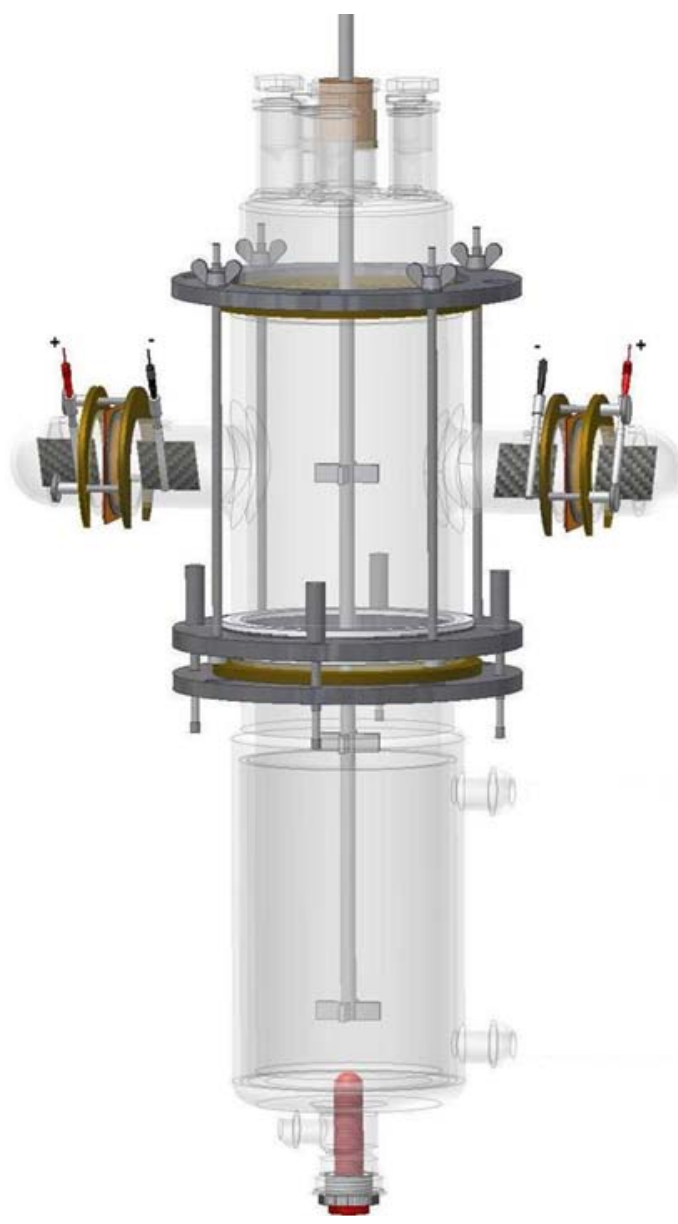

Fig. 5 3.2 L bioreactor with a microbial fuel-cell-like activity sensor. A cathode with a $0.5 \mathrm{M} \mathrm{K}_{3} \mathrm{Fe}(\mathrm{CN})_{6}$ solution is positioned on the right, and the anode in the bioreactor solution is adjacent to it and separated from it by a Nafion proton exchange membrane

a reasonable signal intensity was generated during potentiometric monitoring with a typical baseline at $250 \mathrm{mV}$.

The end of cultivation was marked by decreasing voltage and current values. The current in particular decreased to its initial value after all of the glucose and fructose had been converted. The amperometric signal decreased to a minimum value and then rose again, which indicates that the yeast cells start to consume other nutrients. Proteins in the peptone media may be continuously degraded [9]; they may be the source of metabolic electrons recorded at this point. This means that the microbial activity sensor records not only the sugar metabolism but the metabolic activity in general. This fact should be taken into account when employing the MFC-type activity sensor, and useful information can be obtained in this way in the form of empirical cultivation curves that are characteristic of particular processes.

Based on the recorded results, the amperometric signal provides a better representation of the microbial activity 

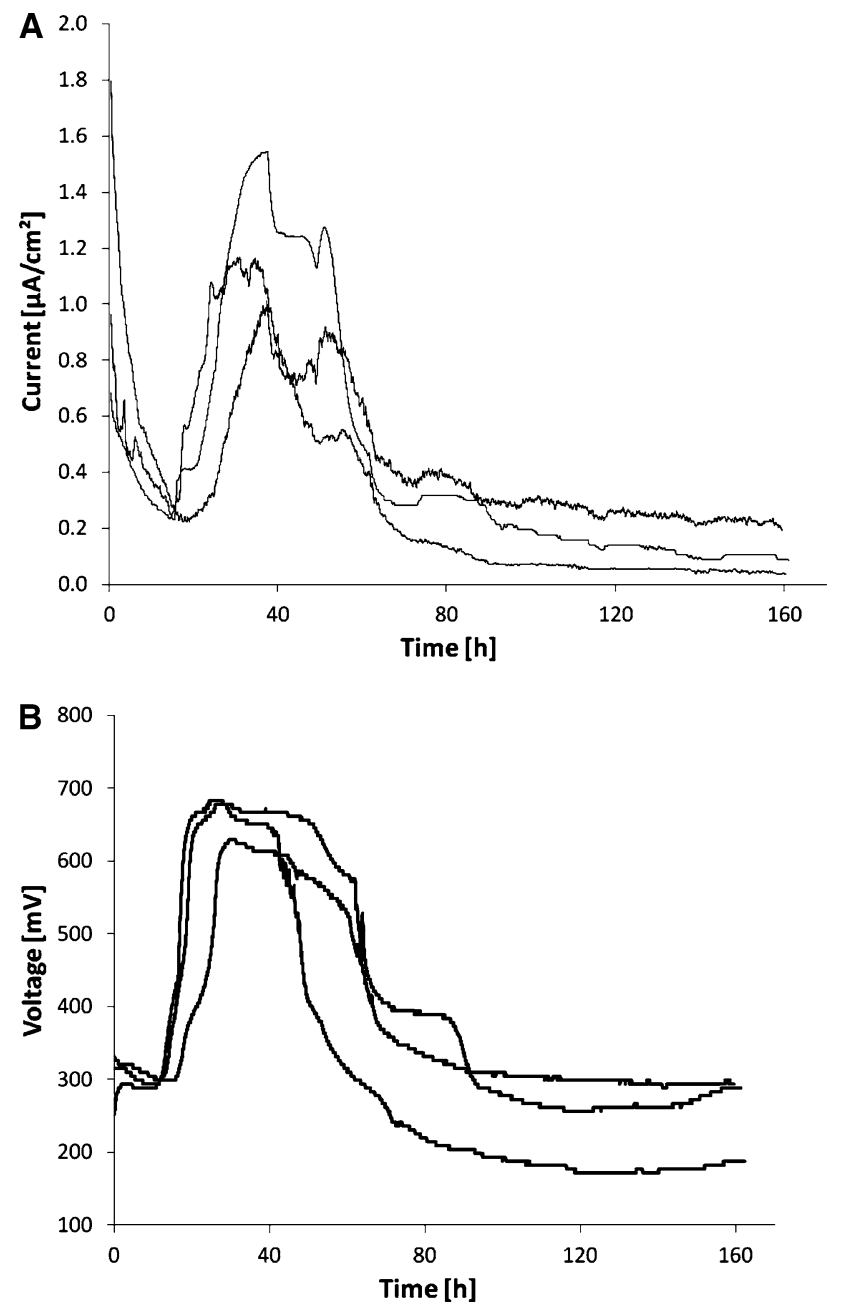

Fig. 6a-b Repeatability of amperometric (a) and potentiometric (b) activity monitoring of a yeast cultivation with a fuel-cell type electrode

because the signal reaches its initial levels at the end of the bioreaction. The potentiometric signal also depends on reduced electroactive compounds in the media; these are not oxidized when voltage measurements are executed, and so the voltage remains high even when the microbial activity decreases. The sluggish oxidation of electroactive compounds in the media is related on the one hand to the low conductivity in the media, and on the other hand to the fact that the nonconducting reactor made of Plexiglas ${ }^{\mathrm{TM}}$ does not function as an oxidation partner.

Repeatability of online monitoring

Form the results obtained with the $500 \mathrm{ml}$ bioreactor, it was concluded that amperometric and potentiometric recordings make an informative combination for further experiments. In addition, it was shown that the measurements could be repeated in the $500 \mathrm{ml}$ bioreactor. To test the repeatability, a $3.2 \mathrm{~L}$ glass bioreactor was constructed with a double wall heat jacket to maintain the temperature at $25^{\circ} \mathrm{C}$ and with two extensions in the upper part for the fuel-cell sensors (Fig. 5). The experiments were executed with YPG in triplicate, yielding a good reproducibility for the bioelectrochemical recordings (Fig. 6). At a rotational speed of $350 \mathrm{rpm}$, oscillations in the amperometric signal were still observed even though the stiring was optimized. Therefore, the values obtained were fitted to an average value by calculating a running median, $\bar{x}_{n}=\frac{1}{N} \sum_{k=0}^{N-1} x_{n-k}$ $(N=6)$.

\section{Conclusions}

The microbial fuel-cell-type activity sensor integrated into a bioreactor is a valuable tool for the online monitoring of microbial cultivation. Ampero- and potentiometric signals indicate the current microbial activity and the progress of carbohydrate conversion to ethanol by yeast. Three measurement setups were tested. The bicathodic combination of ampero- and potentiometric recordings provides the most accurate tool for this kind of cultivation monitoring, and such measurements are reproducible. This combination is possible due to the low conductivity of the bioreactor mixture, which results in a low ohmic drop.

\section{References}

1. Amerine MA, Thoukis G (1958) The glucose-fructose ratio of California grapes. Vitis 1:224-229

2. Barnett JA (2003) A history of research on yeasts 5: the fermentation pathway. Yeast 20:509-543. doi:10.1002/yea.986

3. Barton SC, Gallaway J, Atanassov P (2004) Enzymatic biofuel cells for implantable and microscale devices. Chem Rev 104:4867-4886. doi:10.1021/cr020719k

4. Benetto HP, Stirling JL, Tanaka K, Vega CA (1983) Anodic reactions in microbial fuel-cells. Biotechnol Bioeng 25:559-568. doi:10.1002/bit.260250219

5. Berthels NJ, Cordero Otero RR, Bauer FF, Thevelein JM, Pretorius IS (2004) Discrepancy in glucose and fructose utilisation during fermentation by Saccharomyces cerevisiae wine yeast strains. FEMS Yeast Res 4:683-689. doi:10.1016/j.femsyr. 2004.02.005

6. Bond DR, Lovley DR (2003) Electricity production by Geobacter sulfurreducens attached to electrodes. Appl Environ Microbiol 69:1548-1555. doi:10.1128/AEM.69.3.1548-1555.2003

7. Bullen RA, Arnot TC, Lakeman JB, Walsh FC (2006) Biofuel cells and their development. Biosens Bioelectron 21:20152045

8. He Z, Angenent LT (2006) Application of bacterial biocathodes in microbial fuel cells. Electroanalysis 18:2009-2015. doi: 10.1002/elan.200603628

9. Heilmann J, Logan BE (2006) Production of electricity from proteins using a microbial fuel cell. Water Environ Res 78:531537. doi:10.2175/106143005X73046

10. Holleman-Wiberg (1985) Lehrbuch der anorganischen chemie 91-100. Walter de Gruyter, Berlin, pp 1142-1143 
11. Heller A (2006) Potentially implantable miniature batteries. Anal Bioanal Chem 385:469-473. doi:10.1007/s00216-006-0326-4

12. Holme DJ, Peck H (1998) Analytical biochemistry, 3rd edn. Prentice Hall, Harlow, pp 169

13. Holtmann D, Schrader J, Sell D (2006) Quantitative comparison of the signals of an electrochemical bioactivity sensor during the cultivation of different microorganisms. Biotechnol Lett 28:889896. doi:10.1007/s10529-006-9021-y

14. Kang KH, Jang JK, Phan TH, Moon H, Chang IS, Kim BH (2003) A microbial fuel cell with improved cathode reaction as a low biochemical oxygen demand sensor. Biotechnol Lett 25:13571361. doi:10.1023/A:1024984521699

15. Kim FH, Chang IS, Gil GC, Park HS, Kim HJ (2003) Novel BOD (biological oxygen demand) sensor using mediator-less microbial fuel cell. Biotechnol Lett 25:541-545. doi:10.1023/A: 1022891231369

16. Logan BE (2005) Simultaneous wastewater treatment and biological electricity generation. Water Sci Technol 52:31-37

17. Miyabayashi A, Danielsson B, Mattiasson B (1987) A dual fuelcell for flow-through quantification of microorganisms. Ann N Y Acad Sci 501:555-557. doi:10.1111/j.1749-6632.1987.tb45777.x

18. Niessen J, Schröder U, Harnisch F, Scholz F (2005) Gaining electricity from in situ oxidation of hydrogen produced by fermentative cellulose degradation. Lett Appl Microbiol 41:286290. doi:10.1111/j.1472-765X.2005.01742.x
19. Oh SE, Logan BE (2005) Hydrogen and electricity production from a food processing wastewater using fermentation and microbial fuel cell technologies. Water Res 39:4673-4682. doi: 10.1016/j.watres.2005.09.019

20. Rabaey K, Clauwaert P, Aelterman P, Verstraete W (2005) Tubular microbial fuel cells for efficient electricity generation. Environ Sci Technol 39:8077-8082. doi:10.1021/es050986i

21. Rabaey K, Lissens G, Siciliano SD, Verstraete W (2003) A microbial fuel cell capable of converting glucose to electricity at high rate and efficiency. Biotechnol Lett 25:1531-1535. doi: 10.1023/A:1025484009367

22. Ramon-Protugal F, Pingaud H, Strehaiano P (2004) Metabolic transition step from ethanol consumption to sugar/ethanol. Biotechnol Lett 26:1671-1674. doi:10.1007/s10529-004-3520-5

23. Stickler M, Rhein T (2000) Ullmann's encyclopedia of industrial chemistry (online edition). Wiley-VCH, Weinheim

24. Szucs A, Hitchens GD, JO'M Bockris (1989) On the adsorption of glucose-oxidase at a gold electrode. J Electrochem Soc 136:3748-3755. doi:10.1149/1.2096541

25. Zhang X-C, Halme A (1995) Modeling of a microbial fuel-cell process. Biotechnol Lett 17:809-814. doi:10.1007/BF00129009

26. Zhao F, Harnisch F, Schröder U, Scholz F, Bogdanoff P, Herrmann I (2006) Challenges and constraints of using oxygen cathodes in microbial fuel cells. Environ Sci Technol 40:51935199. doi:10.1021/es060332p 